\title{
PERCURSO FORMATIVO E HOMOAFETIVDADE: HISTÓRIAS E MEMÓRIAS DE ESTUDANTES, CAMPO GRANDE, MS
}

Anaide Bremm ${ }^{1}$

\section{INTRODUÇÃO}

Todos os anos no início do ano letivo, as escolas, em geral, se preparam, abrem suas portas e recebem seus alunos. Então, entram em cena os professores que adentram as salas de aulas, e logo iniciam uma abordagem de apresentação e de boas vindas aos alunos. Hoje vivenciamos salas que perderam suas características de masculinas e femininas, atualmente elas possuem outra composição que são os alunos homoafetivos tanto para meninas quanto para meninos.

Essa nova configuração das salas de aula que antigamente eram divididas por gêneros, hoje não ocorre mais, mas apesar de todo o avanço da legislação que apoia os homoafetivos, ainda, nos deparamos com situações no mínimo vexatórias, quando uma turma de alunos se depara com um colega homoafetivo é o início das piadinhas, deboches e até imitações. Há situações em que os professores tem de intervir, pois as brincadeiras se tornam em algum momento muito agressivas. Os estudantes homoafetivos geralmente não reagem, pelo contrário interiorizam seus sentimentos e a partir daí começam a diminuir a presença na escola, até culminar com o abandono dos seus estudos.

Todavia esse abandono escolar por parte dos alunos homoafetivos é prejudicial como argumenta Spozati (2000, p. 31). Todavia, o processo educativo deve caminhar estrategicamente vinculado aos princípios da equidade, ou seja, da construção de uma sociedade que respeite a diversidade e que saiba conviver com as diferenças, sejam elas de religião, opção sexual, gênero, entre outras opções.

Vale ressaltar que essas diferenças, bem como a construção dos gêneros masculino e feminino são sociais e a escola faz parte dessa sociedade. A escola, em alguns momentos, pode se tornar um lugar agradável e em outros pode criar

\footnotetext{
${ }^{1}$ Discente do Programa de Pós-Graduação Strictu Sensu Mestrado Profissional em Educação na UEMS Campo Grande-MS; anaide_bremm@hotmail.com
} 
situações tão desagradáveis que o indivíduo homoafetivo poderá carregar esse trauma para o resto da vida, como afirma Louro (2013, p.16).

Ao classificar os sujeitos, toda a sociedade estabelece divisões e atribuem rótulos que pretendem fixar as identidades. Ela define, separa e, de formas sutis ou violentas, também distingue e discrimina. Distintas e divergentes representações podem, pois, circular e produzir efeitos sociais.

É fundamental lembrar que esses rótulos e divisões podem surgir na escola, a qual funciona como instituição social dentro de uma determinada comunidade, mas antes de qualquer coisa, ou antes, de tudo, a função da escola é transmitir conhecimentos para os alunos, principalmente ensinar o respeito ao diferente e formar nesse mesmo aluno a sua razão e consciência cidadã dentro dessa mesma sociedade. Esse período escolar também é responsável pela construção das identidades sexuais e pela descoberta da sexualidade.

Porém, essa sexualidade é algo que não pode ser falada abertamente, apenas em grandes confidências, ela passa a ter uma grande vigilância. Mas esquecemos de que a sexualidade está em todo lugar, nas novelas, nos filmes, nas nossas roupas, em todos os lugares, então como podemos escapar dessa sexualidade, criando meios repressores, como afirma Louro (2013).

Através de múltiplas estratégias de disciplinamento, aprendemos a vergonha e a culpa; experimentamos a censura e o controle. Acreditando que as questões da sexualidade são assuntos privados, deixamos de perceber sua dimensão social e política. (LOURO, 2013, p. 27).

A partir da afirmação da autora acima, fica explícito que a sexualidade dentro da instituição escolar sofre vigilância e que os alunos homoafetivos se sintam deslocados por não se adequarem a divisão de gênero estabelecida pela escola e pela sociedade. Mas a homoafetividade sempre esteve ligado à educação como era costume na sociedade grega e romana, o ato sexual entre dois homens era considerado normal, desde os doze anos, essa conscientização social era fundamentada na crença de que os jovens deveriam se aliar aos homens mais velhos para aprenderem filosofia e absorver as virtudes dos mais experientes, essa relação não desabonava a figura do homem, como salienta em seu livro o autor Costa (1992): 
Durante séculos, filósofos, literatos, poetas e moralistas levaram esses ideais a sério; durante séculos, o ideal da ética sexual nada teve a ver com a conjugalidade ou com a parceria homem-mulher, e nem por isso deixou de ser considerado suporte da boa vida política e da boa vida moral. O que atualmente parece estranho, ridículo, segregador ou constrangedor para alguns, um dia foi privilégio dos espíritos elevados e de civilizações que acreditavam representar, no que pensavam, a última e verdadeira palavra da razão humana. (COSTA, 1992. p. 79).

Da mesma forma, como argumenta Costa (1992), essas relações não causavam nenhum dano à sociedade e muito menos a moral dos homens que a praticavam. Na sociedade romana que era semelhante à sociedade grega, essa pratica sexual era vista como normal e aceita pela sociedade desde que ele não praticasse sexo com outro homem da mesma idade que ele, relação sexual entre dois homens era permitido apenas com jovens, pois eles diziam que essa relação era pura, como argumenta Rodriguez (2004, p. 36) "mas se fossem da mesma idade eram execrados pela sociedade romana e em alguns casos até proibidos de exercerem cargos públicos."

Vale lembrar que com a criação do cristianismo essas relações passam ser perseguidas e proibidas. Como a religião cristã tem o seu início dentro da cultura romana, foi exatamente em Roma, durante o reinado do imperador Teodósio no ano 390 D.C., que se tem registro do primeiro castigo corporal aplicado em um homoafetivo. A partir daí, o que antes era permitido, passa a ser impedido. $O$ primeiro ato de proibir foi no reinado do imperador Justiniano no ano de 533 D.C., nos anos de 538 e 544 D.C., todos os homoafetivos foram obrigados a se arrepender de seus atos e obrigados a fazer penitência, pois estavam transgredindo as leis da Igreja.

Entretanto essa rigidez comentada acima durou mil anos, ou seja, toda a Idade Média onde a Igreja criava as regras e todos tinham que obedecer. Por outro lado, surge a Reforma e o Renascimento, os renascentistas alegavam novamente que o homem era o centro das atenções, então vamos exaltá-lo através das artes e da ciência. E a homoafetividade começa novamente a fazer parte do cotidiano europeu, inclusive com alguns reis tendo relacionamentos com outros reis, como argumenta Boswell (1980):

Como quer que seja, sempre que pensamos em relações eróticas entre homens, raramente pensamos em Sócrates, Júlio Cesar, Adriano. Ricardo Coração de Leão, nos heróis das epopeias gregas como Aquiles e 
Pátrocles, ou no fato de que, dos quinze primeiros imperadores romanos Claudio foi o único exclusivamente heterossexual (BOSWELL, 1980, p. 61).

Essas relações homoafetivas, citadas pelo autor acima, não eram questionadas pela sociedade, elas faziam parte da cultura clássica, esses homens eram grandes representantes na política, tinham o poder de controlar um terço do mundo, mesmo mantendo relações com outros homens. Mas novamente a homoafetividade foi ameaçada, então durante a peste negra que assolou a Europa e matou mais de 25 milhões de pessoas, a lgreja desejosa de retomar o poder resolve culpar alguém pela desgraça ocorrida, o homoafetivo, judeu e herege se tornam os culpados pelos pecados da humanidade e são perseguidos. O que era um problema de saúde pública e falta de higiene se torna "pecado" e os pecadores foram mortos em nome do bem de todos. Em relação às normatizações após Idade Média Focault (2012) faz uma crítica:

A pastoral cristã inscreveu como dever fundamental, a tarefa de fazer passar tudo o que se relaciona com o sexo pelo crivo interminável da palavra. A interdição de certas palavras, a decência das expressões, todas as censuras do vocabulário poderiam muito bem ser dispositivos secundários com relação sujeição: maneiras de torná-la moralmente aceitável e tecnicamente útil. (FOUCAULT, 2012, p. 27).

É fundamental lembrar que a Igreja assume então o papel de intermediária para controlar e reprimir através da confissão os desejos da carne e a pastoral entra como um filtro de moralidade, mas ela não obteve sucesso em acabar com a sexualidade, então, dessa forma ela direciona essa mesma sexualidade para a procriação.

No que diz respeito ao assunto, atualmente a lgreja não possui mais esse poder normatizador, mas também sentimos muita dificuldade em falar sobre sexo e sexualidade. Pensando dessa forma, a Constituição Federal de 1988 e a Lei de Diretrizes e Bases (LDB, 1996, p. 293) concordam dizendo:

A educação, dever da família e do Estado, inspirado nos princípios de liberdade e nos ideais de solidariedade humana tem por finalidade o pleno desenvolvimento do educando, seu preparo para o exercício da cidadania e sua qualificação para o trabalho (LDB, 1996, p. 293). 
Portanto esses ideais de identidade de sentimentos, de ideias e doutrinas humanas mantidas pela Constituição Brasileira e pela LDB/96 não estão sendo aplicadas na escola pública de nossa pesquisa. Pelo contrário os dados demonstram que não é isso que vivenciamos nas escolas, principalmente pelos motivos já comentados anteriormente, a homoafetividade, até hoje, é um assunto tabu, difícil de ser comentado ou até mesmo de ser conversado, nem todos os professores tem uma postura pedagógica para abordar o assunto e os alunos, na maioria das vezes, não estão maduros o suficiente para discutirem sobre sexualidade ou orientação sexual.

É importante que os professores se mostrem disponíveis e ofereçam segurança para os alunos abordarem este tema polêmico e a escola deve também problematizar e discutir esses assuntos. Porém o preconceito e a aceitação da sociedade e mesmo da família até então, persistem não oferecendo um direito que está estabelecido na Constituição Brasileira, artigo 3ํㅜㄹ parágrafo IV que diz: "promover o bem de todos, sem preconceitos de origem, raça, sexo, cor, idade e quaisquer outras formas de discriminações."

Vale lembrar que 0 artigo $3^{0}$ da nossa Constituição nem sempre é cumprido na comunidade escolar. Para tal o professor tem que estar sempre atento e perceber o momento certo de abordar o assunto, quando há uma piada sem graça, ou um apelido constrangedor e até mesmo uma brincadeira mais ofensiva, nesse momento ele deve abordar o tema sobre sexualidade e preconceito como está explicado nos PCN (2000):

\begin{abstract}
Atualmente, reivindica-se a inclusão da categoria de gênero, assim como etnia, na análise dos fenômenos sociais, com o objetivo de retirar da invisibilidade as diferenças existentes entre os seres humanos que, por vezes, encobrem discriminações (PCN, 2000, p. 322).
\end{abstract}

Portanto, mesmo com todas essas determinações dos Parâmetros Curriculares Nacionais, falta o investimento na formação de professores, um mapeamento e divulgação das experiências pedagógicas na escola onde será feita a pesquisa. Segundo esse documento a sexualidade e a orientação sexual tem que ser discutida em sala pelos professores e dessa forma provocar uma reflexão amenizar o preconceito vigente na sociedade escolar, conforme diz no PCN (2000): 
Com a inclusão da Orientação Sexual nas escolas, a discussão de questões polêmicas e delicadas, como masturbação, iniciação sexual, o "ficar" e o namoro, homossexualidade, aborto, disfunções sexuais, prostituição e pornografia, dentro de uma perspectiva democrática e pluralista, em muito contribui para o bem-estar das crianças, dos adolescentes e dos jovens na vivência de sua sexualidade atual e futura. (PCN, 2000, p. 293).

Contudo apesar de toda essa orientação acima dos PCN, os livros de biologia adotados na escola Hércules Maymone, particularmente, não trazem o assunto da diversidade sexual, nem ao menos o avanço dos direitos do homoafetivo dentro da educação brasileira. No entanto, os PCN trouxeram, não só, para a escola um grande avanço educacional no contexto da sexualidade, mas também para a sociedade brasileira. Mas lamentavelmente a diversidade sexual é pouco praticada nas escolas, pois surgem vários questionamentos entre os docentes responsáveis por reproduzir de forma correta aos alunos em sala de aula a temática da sexualidade.

Dentre os questionamentos acima entendo a necessidade de trabalhar com os professores, mas objetivo da pesquisa por hora são os estudantes homoafetivos. O problema da pesquisa é responder se esses mesmos alunos estão se sentindo a vontade e amparados na escola do Ensino Médio da rede pública de Campo Grande, para continuarem seus estudos sem abandonar a escola.

\section{DESENVOLVIMENTO DA PESQUISA}

Por outro lado, apesar do PCN e do Projeto Pedagógico (PP), da escola Estadual de Campo Grande, não encontrei nenhum trabalho desenvolvido nessa área. Após conversar com docentes da área de biologia de forma informal, percebi que mesmo o tema sexualidade estar dentro dos Parâmetros Curriculares Nacionais (PCN) e do Projeto Pedagógico (PP), os professores alegaram não trabalharem este tema, ficando restritas a gravidez, doenças sexualmente transmissíveis (DST) e divisão de gêneros. Esta problemática se deve ao fato dos docentes não se sentirem a vontade de abordar um tema tão delicado, alguns alegam que não receberam capacitação para trabalharem o tema, então resolveram não abordar o assunto em sala de aula.

Seria oportuno lembrar que para contribuir com o Governo Federal criou um material didático em 2011, conhecido como Kit educativo anti-homofobia que 
consistia em seis volumes de revistas em quadrinhos com foco no público adolescentes e que abordariam prevenção de doenças sexualmente transmissíveis (DST) e AIDS e as relações homoafetivas, mas acabou sendo vetado por pressão da bancada evangélica no Congresso Nacional. O Kit foi elaborado numa parceria entre os ministérios da Educação e Saúde, a Organização das Nações Unidas para a Educação, a Ciência e a Cultura (UNESCO), o Fundo das Nações Unidas para a Infância (UNICEF) e o Fundo de População das Nações Unidas (UNFPA), durante a gestão de José Gomes Temporão que era Ministro da Saúde. A presidenta Dilma Rousseff vetou a produção e distribuição deste material, o que seria benéfico para os docentes trabalharem nas escolas Públicas e Privadas em 2011.

\section{REVISÃO BIBLIOGRÁFICA}

Utilizarei para a pesquisa contribuições do médico psiquiatra, neurologista e pai da psicanálise, Sigmund Freud, pois acredito que através dele conseguirei entender a essência e os movimentos sociais dos homoafetivos.

Segundo as suas investigações psicanalíticas, Freud compara a necessidade sexual do homem a fome e como tal ela precisa ser saciada. "O fato da existência de necessidades sexuais no homem e no animal expressa-se na biologia pelo pressuposto de uma "pulsão sexual". Segue-se nisso a analogia com a pulsão da nutrição: a fome". (FREUD, 2002, p.13).

Portanto para Freud os homoafetivos são chamados de invertidos, ele busca na mitologia grega a inspiração para explicar o surgimento dos invertidos, na fábula o ser humano é dividido em duas metades, um homem e uma mulher e essas metades após a divisão se procuram para se tornarem completas. Mas a metade homem cujo objeto sexual seria a mulher passa a procurar a outra metade masculina para ser seu objeto sexual, o mesmo ocorre com a metade mulher que procura outra metade feminina para ser seu objeto sexual, não a metade masculina como seria normal, para essas pessoas que possuem o sexo ao contrário Freud cria a terminologia de invertidos (FREUD, 2002, p. 14).

Segundo o autor acima, a inversão que hoje chamamos de homoafetividade pode ser desencadeada por um trauma ou algo muito triste e que surge na puberdade como explica Freud (2002): 
O traço da inversão pode vir de longa data no indivíduo, até onde sua memória pode alcançar, ou só se ter feito notar em determinada época, antes ou depois da puberdade. Esse caráter pode conservar-se por toda a vida, ou ser temporariamente suspenso, ou ainda constituir um episódio no caminho para o desenvolvimento normal (FREUD, 2002, p. 15).

Dessa forma a inversão ocorre, acima de tudo, pelo o que aconteceu na infância, se a educação foi normal, realizada pelo pai e pela mãe, não ocorre à inversão, mas se de alguma forma faltou um desses pais por algum motivo haverá a troca de papéis e então a inversão poderá acontecer, desviando o foco do objeto sexual. Fazendo uma ligação com o pensamento freudiano e com o objeto desta pesquisa podemos dizer que essa é uma realidade atual, conforme argumenta Freud (2002):

Em muitos histéricos, vê-se que a ausência precoce de um dos pais (por morte, divórcio ou separação), em função da qual o remanescente absorveu a totalidade do amor da criança, foi o determinante do sexo da pessoa posteriormente escolhida como objeto sexual, com isso possibilitando-se a inversão permanente FREUD, (2002, p.107).

Da mesma forma observando os alunos homoafetivos hoje, percebo que grande parte deles não possui os pais juntos, alguns foram criados pela mãe, outros apenas pelo pai e outros foram criados pelos avós desencadeando a inversão acima citada por Freud (2002, p.107).

Por outro lado, além de Freud, pretendo utilizar algumas contribuições do filósofo e psicólogo Paul Michel Foucault (1926-1984), que foi um dos principais pensadores da pós-modernidade, que centrou suas pesquisas em temas com instituições penais, a sexualidade e o poder. Segundo Foucault o tratamento científico dado à sexualidade, no qual o comportamento sexual é normatizado por meio do convencimento racional dos indivíduos sobre os cuidados necessários à sua vida nesse âmbito. Uma dessas normatizações é a mecânica do poder como argumenta Foucault (2012):

A mecânica do poder que ardorosamente persegue todo esse despropósito só pretende suprimi-lo atribuindo-lhe uma realidade analítica, visível e permanente: encrava-o nos corpos, introdu-lo nas condutas, torna-o princípio de classificação e de inteligibilidade e o constitui em razão de ser e ordem natural da desordem. (FOUCAULT, 2012. p. 51). 
Desse modo vivemos hoje numa sociedade considerada aberta a novidades, até então, vivemos sob o jugo do poder, esse mesmo poder político, religioso, econômico e social ainda nos controla, mas de maneira sutil para que não percebamos seu domínio totalitário sobre a sociedade. E nossos desejos, até esse tempo, permanecem escondidos não podemos mostrá-los, pois dessa forma estaríamos contrariando a normatização estabelecida pelos órgãos do poder.

Entretanto a escolha desses referenciais teóricos deve-se a necessidade de refletirmos sobre as políticas da sexualidade e como trabalharmos esse assunto em sala de aula. O tema da sexualidade nas escolas é algo que vem desde o século XVIII, onde houve uma preocupação em falar e fazer falar sobre sexo, de acordo com Foucault (2012):

\footnotetext{
Seria inexato dizer que a instituição pedagógica impôs um silêncio geral ao sexo das crianças e dos adolescentes. Pelo contrário, desde o século XVIII, ela concentrou formas do discurso neste tema; estabeleceu pontos de implantação diferentes; codificou os conteúdos e qualificou os locutores. (FOUCAULT, 2012, p 37).
}

$\mathrm{Na}$ perspectiva de que a escola tem como função educar e preparar o jovem para a vida através de movimentos sociais, culturais, políticos e religioso. Dessa maneira percebo que é possível a elevação cultural da sociedade a partir de uma formação política e crítica dos jovens, através dos PCN, que se forem aplicados corretamente contribuirão para a formação de uma classe de cidadãos mais livres e críticos perante as diferenças que os cercam sem partir para o preconceito.

\section{OBJETIVOS OBJETIVO GERAL}

Discutir a diversidade sexual na escola com o objeto do homoerotismo, para compreender as percepções de alunos sobre gênero, sexualidade e homofobia, bem como eles lidam com tais temáticas na prática docente.

\section{OBJETIVOS ESPECÍFICOS}


- Compreender como os alunos se percebem dentro da questão da diversidade sexual, levantando pontos positivos e negativos.

- Perceber como os alunos reagem à homofobia na escola.

\section{METODOLOGIA E MÉTODO DE PESQUISA}

A pesquisa será baseada no método da fenomenologia que é o estudo daquilo, daquela coisa, daquele algo, daquele objeto que é dado à consciência, que nos faz pensar nele (a) e do (a) qual falamos, como argumenta Ribeiro Junior (2003, p. 8), a qual será realizada dentro de uma abordagem qualitativa que é empregada, para a compreensão de fenômenos, que compreende a relação sujeito/objeto para os estudos interpretativos e discute a história de vida como uma de suas ferramentas mais valiosas quando se trata de analisar a intersecção entre a vida individual e o contexto social.

A metodologia será fundamentada na Educação entre Pares de linha participativa que utiliza técnicas de dinâmica como as oficinas; esse processo se inicia a partir da experiência e do conhecimento dos próprios participantes por meio da conexão entre os novos conceitos e aquilo que os participantes já sabem. Nessas narrativas vamos buscar soluções para problemas comuns a adolescentes e jovens, mudanças de atitudes discriminatórias levando a outras mais igualitárias e propiciar reflexões. Ao longo da escrita, portanto, destaco a escola como ambiente privilegiado para debate das questões de diversidade sexual e de gênero, contribuindo para a diminuição da homofobia, entendendo que essa perseverança coopera na formação dos sujeitos e de suas identidades.

Em cada oficina serão indicados: título, objetivos e material necessário de orientações para a atuação dos facilitadores. Assim, iremos nos reunir com os alunos no contra turno das aulas normais. Acreditamos que as oficinas nos proporcionarão um aprofundamento na temática e permitirá aos alunos contarem suas histórias de vida com uma liberdade maior para expor ideias, sentimentos e experiências, quanto à diversidade sexual na cultura escolar, em relação a padrões de comportamento e discursos predominantes na escola.

Todas as oficinas serão gravadas, escritas, transcritas e analisadas a partir da autorização por escrito das participantes, através do Termo de 
Consentimento Livre e Esclarecido e da entrega do Termo de Confidencialidade. O projeto será registrado no comitê de ética da UEMS em 2015.

\section{CONSIDERAÇÕES FINAIS}

A educação humanista não ensina apenas conteúdos curriculares, ela foca no indivíduo como um todo e como ele se relaciona com o mundo dos objetos, segundo Bicudo (2006). A Escola é o principal ambiente para o debate e a superação das diferenças sexuais e sociais, pois dentro dela que ocorre a formação do indivíduo, onde ele recebe as primeiras concepções da sociedade da qual ele faz parte ideia em conformidade com Louro (2013). Mas para que isso ocorra é necessário que reveja os conteúdos de acordo com os PCN, o professor é o principal agente formador e orientador dessas práticas, mas para isso ele tem que estar preparado para além dos aspectos fundamentais de ensino e isso significa estar aberto aos novos comportamentos sociais. Nesse sentido Bicudo (2006, p. 5) argumenta que: "A educação centrada no aluno se apresenta como uma atitude assumida para com o aluno e para com o próprio ato de educar". O homem está em contínuo processo de crescimento e aprendizagem, porque realiza os objetivos primários da vida que são os valores.

\section{REFERÊNCIAS}

BICUDO, Maria Aparecida Viggiani. A Filosofia da Educação Centrada no Aluno. 2. Ed. São Paulo: Centauro, 2006.

BOSWELL, John. Christianity, social tolerance, and homosexuality.Chicago e Londres, The University of Chicago Press, 1980.

BRASIL, Jornal do. Kit Gay. Disponível em:<http://www.jb.com.br>. Acesso em: 25 mai. 2011.

BRASIL. Lei de Diretrizes e Bases da Educação Nacional (LDB): Lei no 9.394, de 20 de Dezembro de 1996. Brasília, 1996.

BRASIL. Constituição Federal: art. 205. Brasília, 1988.

BRASIL. Parâmetros Curriculares Nacionais do Ensino Médio (PCNs): Brasília, 26 de Junho de 1998. 
COSTA, Jurandir Freire. A inocência e o vício: estudos sobre o homoerotismo. Rio de Janeiro: Relume-Dumará, 1992.

FOUCAULT, Michel. História da Sexualidade. São Paulo: Graal, 2012.

FREUD, Sigmund. Três Ensaios sobre a Teoria da Sexualidade. Rio de Janeiro: Imago, 2002.

RIBEIRO JUNIOR, João. Introdução à Fenomenologia. Campinas: Edicamp, 2003.

LOURO, Guacira Lopes. 0 corpo educado: pedagogias da sexualidade. $3^{\mathrm{a}} \mathrm{Ed}$. Belo Horizonte: Autêntica Editora, 2013.

RODRIGUES, Humberto. O amor entre iguais. São Paulo: Editora Mythos, 2004.

SPOSATI, Aldaíza de Oliveira. Exclusão social e fracasso escolar, Em Aberto, Brasília: v. 17, n. 71, p. 21-32, jan. 2000. 